\title{
Thoughts on Thinking: Engaging Novice Music Students in Metacognition
}

\author{
MEGHAN BATHGATE ${ }^{1} *$, JUDITH SIMS-KNIGHT ${ }^{2}$ and CHRISTIAN SCHUNN ${ }^{1}$ \\ ${ }^{1}$ Learning Research \& Development Center, University of Pittsburgh, Pittsburgh, USA \\ ${ }^{2}$ University of Massachusetts, Dartmouth, North Dartmouth, USA
}

\begin{abstract}
Summary: Achieving expertise in any area requires extensive practice and engagement with the subject one desires to master. As not all practice yields good progress, methods must be found that lead learners to practice effectively. Many experts employ highly tailored practice involving metacognitive processes, but novices rarely engage in frequent and explicit metacognitive strategies during practice. As a result, novice progress may be impeded through repetition of systematic errors and ineffective techniques. Our study provides evidence of the effectiveness of teaching metacognition to novice music students through weekly lessons. Thirty-five adolescent students of six instructors were randomly assigned to metacognitive focus or existing practice teaching conditions. Students receiving metacognitive teaching achieved higher performance ratings when compared with students receiving control instruction, even though practice time did not vary between groups. These results suggest that having students explicitly verbalize and reflect on their learning process produces more efficient practice and greater end performance. Copyright $@$ 2011 John Wiley \& Sons, Ltd.
\end{abstract}

The ability of musicians to mentally maintain large, complex pieces of information while performing the dual task of fine motor performance is impressive for both audiences and cognitive scientists alike. The extensive engagement and practice necessary to produce this expert performance offers insight into the cognitive changes involved in learning a complex skill. Thus, expertise and skill acquisition literature has frequently used music education and performance as a platform for understanding the progression from novice to expert (e.g. Eccles \& Feltovich, 2008; Ericsson, Krampe, \& Tesch-Romer, 1993; Palmer \& Meyer, 2000; Sloboda, Davidson, Howe, \& Moore, 1996). Similar to other domains such as physics and the medical field, the quality of cognitive strategies in musicians deepens with increasing expertise (Barry \& Hallam, 2002; Siegler, 1996; Sternberg, 1998; Lesgold et al., 1988), as does the representation of one's understanding of the domain (Chi, Feltovich, \& Glaser, 1981; Cantwell \& Millard, 1994; Grumko, 1993; Lehmann \& Ericsson, 1997).

In addition to performance differences, practice strategies vary between expert and novice musicians, with novices demonstrating less well-defined practice strategies than the organized study techniques experts routinely employ (Ericsson et al., 1993; McPherson \& Renwick, 2001). For example, McPherson and Renwick's (2001) longitudinal analysis of young students' practice found that over $90 \%$ of novice practice time consisted of playing straight through a piece once or twice without consideration of the deliberate practice techniques routinely utilized by experts. Hallam (2001a) also found this strategy to be most common in beginners. Such basic practice is disparate in depth and quality from expert practice in which one common strategy involves segmenting large sections of music into smaller passages to allow for the development and refinement of specific techniques (Hallam, 2001a, 2001b).

Study strategies do vary across expert musicians. In fact, different experts often prefer different practice organization,

*Correspondence to: Meghan Bathgate, Learning Research \& Development Center, University of Pittsburgh, 3939 O'Hara St., Pittsburgh, PA 15260, USA. E-mail: meb139@pitt.edu rehearsal, and performance strategies (Zimmerman, 1998). Nonetheless, one strategic element that experts uniformly use is metacognition (i.e. the active reflective awareness of one's process and progress towards a goal) (Hallam, 2001a, 2001b; Sternberg, 1998). The metacognitive understanding experts apply provides them with an awareness of task requirements, an understanding of appropriate strategies available for selection, and the efficacy of these strategies on their performance and learning (Flavell, 1979; Pintrich, 2002). Specifically in music, the reflective nature of metacognitive practice allows each performer to explicitly understand the task demands of a musical piece, identify potentially difficult passages, select appropriate cognitive and physical strategies that work best for them, and decide how to effectively structure their practice time in relation to such factors.

This degree of reflection is initially lacking in novice music students' practice. Hallam (2001b) found discrepancy in the use of metacognition between expert and novice musicians with regard to their practice and performance preparation. Experts were explicitly aware of their techniques, as well as the effectiveness such techniques had on their practice and performance ability. Additionally, experts were highly attuned to specific weaknesses in their playing and explicitly devoted practice time to target weaknesses, often through the use of highly concentrated, meticulous rehearsal. In contrast, novices in Hallam's study generally lacked metacognitive reflection in their practice, preventing the students from defining their weaknesses and developing effective strategies to address them. In turn, this resulted in repetition of errors paired with less systematic and effective strategies drawn into aid in overcoming difficult passages. Such problems are especially pressing for instrumental students, where the majority of their practice and development occurs outside of the lesson. For most of their practice, immediate expert feedback and guidance is not available.

Although the importance and impact of frequent practice should not be underestimated (e.g. Ericsson et al., 1993; Sloboda et al., 1996), developing reflective awareness in relation to one's practice appears critical in making practice deliberate, the kind of practice generally argued to most efficiently 
produce expert performance (Ericsson et al., 1993). Increases in domain knowledge paired with the challenge of increasingly difficult pieces require performers to reflect deeply on the efficacy of their strategies if they are to progress significantly beyond a beginning level. Use of such metacognition has been shown to correlate with skill development, with experts showing substantially more awareness of their strategies than other players (Barry \& Hallam, 2002; Hallam, 2001a, 2001b). McPherson (2005) found that in some areas of performance (e.g. playing by memory, sight reading, playing by ear), the use of mental strategies during early learning of the technique was more influential than overall practice time.

In general, self-regulative strategies, such as metacognition, allow learners to understand the connection between their strategies and progress, increasing their selection and application of effective strategies to their practice (Zimmerman, 1990). Through this process, students are able to adapt strategies that are beneficial to skill development and their individual learning needs. Furthermore, the use of such self-regulatory strategies is related to increases in self-efficacy and motivation (Zimmerman, 1998), both of which are key predictors in music competence (McPherson \& McCormick, 2006).

Although metacognitive techniques are not generally people's initial approach to a problem solving, Berardi-Coletta, Buyer, Dominowski, and Rillinger (1995) demonstrated that participants could use metacognitive approaches when prompted. Using problem-solving tasks such as the Tower of Hanoi and Katona card problem, Berardi-Coletta et al. found that groups encouraged to think metacognitively by being asked to verbally reflect on the reasons behind their actions (e.g. 'How are you deciding on a way to work out the order for the cards?', p. 211) performed better than control groups and groups that were encouraged to focus on the problem-area of the task (e.g. 'What is the goals of the problem?' p. 211). Asking participants to describe their mental strategies drove attention away from the immediate problem space and directed it to the process level. Asking individuals about the nature and quality of their actions (e.g. 'How are you deciding what went wrong?') forced them to reflect on their cognitive process, led to increases in the transfer of conceptual knowledge across tasks, and produced the greatest frequency and range of process-level responses.

Similar findings have been shown in the realm of music learning. Hallam (2001a, 2001b) and McPherson (2005) explicitly asked both expert and novice musicians to explain their process in learning a new piece, and both the experts and novices were able to provide explanations. However, only the experts were able to express the reasoning for their particular strategy and were clearly aware of their strengths and weaknesses. Although research has delineated these important differences in metacognition and learning, the potential impact of pushing novice students to adopt a metacognitive approach has not been fully explored. A number of researchers have suggested implementing the use of reflective practices when teaching students and encouraging metacognitive thinking to enable them to consciously consider their approach and evaluate its success (Barry \& Hallam, 2002; Hallam, 2001a, 2001b; McPherson, 2005; McPherson \& Renwick, 2001; Parncutt \& McPherson, 2002). Teaching students to ask questions, explain their processes, and reflect on performance may increase their quality of playing, study habits, and their ability to transfer their learning across a variety of musical pieces (Pintrich, 2002). Instrumental teachers vary in the degree to which they explicitly teach practicing techniques, set goals, provide specific versus general feedback, and encourage verbalization in their students (Duke, 1999/2000; McPherson \& Renwick, 2001). In light of these findings, our current study seeks to provide evidence that teaching metacognitive practice strategies to beginner music students is beneficial to their practice and performance.

\section{METHOD}

\section{Participants and recruitment}

Forty-five music students of six music instructors from two New England music studios were recruited. Lessons consisted of a half hour, private 1:1 instruction conducted weekly. The six instructors had previously attended college for music education and had been teaching between 13 and 41 years $(M=25.2)$. Students ranged in age from 13 to 19 years old $(M=14.7, S D=1.4)$, and gender was relatively even $(60 \%$ female). All students studied piano, guitar, or bass guitar; most (67\%) had been playing for 3 years or less ( $M=34.0$ months, $S D=21.3$ months). All students were able to read basic music notation.

\section{Materials}

\section{Metacognitive brochure}

Instructors were trained in metacognitive teaching with the use of a 'Metacognitive Brochure'. The brochure was constructed for the purpose of this study and reviewed the concept of metacognition related to music and provided concrete examples taken from Hallam (2001a, 2001b) and Berardi-Coletta et al. (1995).

\section{Lesson forms}

Instructors were given a 'Post-Lesson Form' asking the degree to which they believed they taught metacognitive teaching in their lesson ('yes', 'somewhat', 'no') and if they believed each student was receptive to the teaching ('yes', 'somewhat', 'no'). Additionally, instructors were encouraged to write down any remarks, questions, or problems that arose during the lessons. Students also received a weekly 'Practice Sheet' asking the number of times they practiced that week and the length of time they practiced each session. Following metacognitive teaching lessons only, the practice sheet also asked the student if they felt they used metacognition during their lesson ('yes', 'somewhat', 'no'). Only 25 students $(55 \%)$ completed the metacognitive debriefing information.

\section{Digital recorders}

Digital recorders were provided for the teachers to record students' performances.

\section{Surveys}

Students received Ritchie and Williamon's (2007) General Musical Self-efficacy Scale, on the basis of the 'General Self-Efficacy Scale' of Sherer et al. (1982), with alterations 
adapted specifically for music. Specifically, we focused on the 17 items regarding students' perceptions of their ability to learn their instrument $(a=.91)$. These questions asked students about their belief in their ability to learn their instrument, in addition to questions regarding how students proceed with difficulties when learning.

\section{Performance pieces}

Each condition consisted of three pieces at different difficulty levels (easy, medium, difficult), resulting in a total of six pieces to be played across the two conditions. An expert music teacher selected all pieces so that the pieces in both conditions were comparable. Students' instructors selected the difficulty level for each student. Being that each student played one song per condition, this resulted in two performance pieces per child at his or her difficulty level.

\section{Procedure}

\section{Music instruction}

For control instruction, teachers were asked to teach as they had been prior to our training, which consisted largely of instructor guidance and modeling, with the instructor providing most of the input and discussion. In a typical control lesson, instructors would review that week's song/lesson with the student, model proper playing, allow the student to practice certain techniques or passages (generally specified by the instructor), and decide whether to move on to a new piece or assign the song again in the coming week.

Teachers were trained in metacognitive teaching directly prior to teaching using the metacognitive instruction method. The topic of metacognition was thoroughly discussed with instructors, and training was performed through a 1:1 discussion session with the use of a 'Metacognitive Brochure', which provided instructors a guide with examples to help in their teaching. Overall, teachers had control over exactly how they integrated the metacognitive steps into their lessons, as would be the case in broader applications of metacognitive instruction. Further, an exact script to be used by all teachers in all settings was thought to be potentially disruptive of particular teacher-student dynamics that were already established, especially across instrument types and various levels of playing. The next paragraph describes the common elements that the instructors were asked to include.

During instruction, the metacognitive training involved multiple activity stages, as shown in Figure 1. The 'Planning' stage included analyzing a piece prior to performing, identifying key features, finding patterns, and naming parts that may seem difficult. Students were continuously encouraged to provide examples and verbalize the strategies they might use to play sections of the piece. 'Playing' consisted of the student playing the song while being encouraged to actively listen to the sound they were producing. The 'Evaluation' stage consisted of the student identifying difficulties and successes, discussing the strategies she or he employed, and assessing whether they were successful in helping the student learn the song. "New strategies' were discussed by having students describe new ways they could approach/practice parts of the song if their strategies were not successful. The student then planned how these new strategies could be incorporated into their playing and subsequently replayed the song.

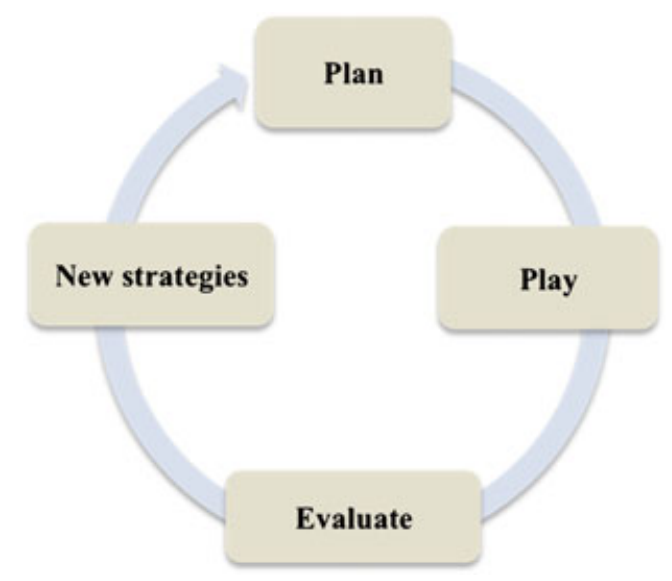

Figure 1. Basic design of metacognitive teaching structure

This overall cycle of metacognitive stages was implemented several times throughout the lesson, and students were encouraged to use this reflective process during their home practice. Throughout the training, instructors were told to encourage students to verbalize their process and discuss possible strategies they could use during playing and practicing.

\section{Design}

The study used a within-subjects design for instructional approaches with order counter-balanced across the six instructors, with three instructors randomly assigned to begin with control teaching and the other three instructors beginning with metacognitive teaching. Those first assigned to metacognitive teaching (Order 1) were trained at this point, whereas the three remaining teachers (Order 2) were not trained until after the control condition instruction to minimize contamination of instructional approach. Using their assigned technique, instructors introduced the teaching using the musical piece the student had been currently learning prior to the study. After 2 weeks of teaching, students were given a piece of music to learn for a recorded performance. Each piece had an easy, medium, and difficult level, and the students' instructors chose the level best suited to each student. Following 2 weeks of practice with this piece, each student performed their piece while being audio recorded by their instructor.

After the first recording was collected, the instructors were asked to switch instruction approach. That is, those who had begun with control teaching switched to metacognitive teaching (and received training on metacognitive teaching at this point), and those who had begun with metacognitive teaching returned to their standard (control) teaching. Consistent with the first instructional phase, the first 2 weeks of this second instructional phase involved students learning a piece of music as part of their instructor's usual lesson plan, with the inclusion of the particular teaching techniques. Following these 2 weeks, students were given a second performance piece. After 2 weeks of practice with this piece, the students were recorded while performing their second piece (see Figure 2).

In this counterbalanced experimental design, there are three key contrasts: (i) between condition at Time 1 tests the benefit of instructional method; (ii) from Time 1 to Time 2 within Order 2 to provide a second test of the benefits of instructional method; and (iii) from Time 1 to Time 2 within Order 1 to test the retention of the intervention. The contrast 


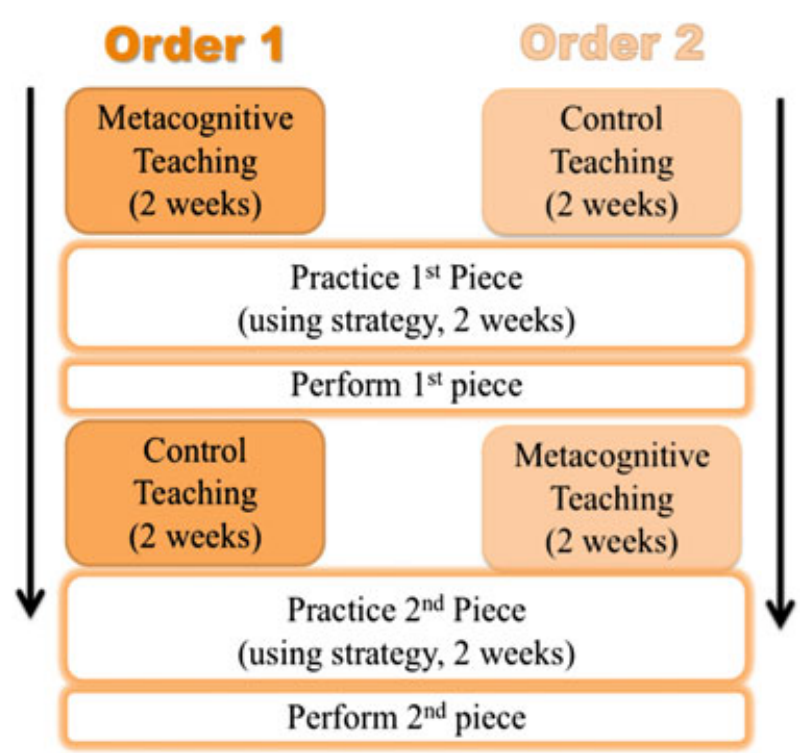

Figure 2. Design and procedure of teaching conditions

between conditions at Time 2 is more complex because it mixes transfer and intervention components.

Practice information from the students (number of sessions and length of sessions that week) and Post-Lesson Forms from the instructors were gathered at the conclusion of each lesson throughout the study. Practice sheets were collected weekly from students by all but one teacher, who collected them only once at the start of each condition. Of the possible 160 collection sheets, 123 were returned for the metacognitive condition (77\%) and 113 of the 160 were returned in the control condition $(71 \%)$.

\section{Survey and self-efficacy measures}

Self-efficacy was measured three times: prior to starting the first teaching condition and following each teaching condition. The full music survey (including the metacognitive questions; described above) was given to students following the metacognitive condition.

\section{Ratings of performed pieces}

Three professional musicians were chosen to rate the recorded performances, using the same rating scale across all instrument types. Each musician had a background in music education and was blind to condition and purpose of the study. Recordings were randomly presented and rated on rhythm (how consistently did the student kept the beat of the song?, Cronbach $\alpha$ for ratings by the three musicians $=.80$ ), errors (did the student make many errors throughout the recording, $\alpha=.68$ ), and overall musicality (the overall 'feel' and articulation of the song, $\alpha=.85$ ). All scales were on a 1-7 Likert scale ranging from very poor to excellent. Performance and practice data from students from one teacher were removed because of mislabeling of files.

\section{RESULTS}

\section{Use of metacognition manipulation check}

The metacognitive post-lesson form was analyzed to examine whether instructors followed the metacognitive instruction plan in that condition. Instructors reported doing so overall: instructors responded 'yes' to using metacognitive teaching during their lessons $72 \%$ of the time, 'somewhat' $24 \%$ of the time, and 'no' 4\%. Additionally, instructors reported 'yes' students were receptive to the metacognitive teaching $67 \%$ of the time, 'somewhat' $27 \%$ of the time, and 'no' $6 \%$ of the time.

The students who completed the metacognitive debriefing survey reported feeling that ('yes') they had used metacognition during a lesson $55 \%$ of the time and at least 'somewhat' $40 \%$ of the time, with $5 \%$ saying 'no.' Interestingly, the instructors' responses were not significantly correlated with the students' perception of the use of metacognition. Nonetheless, whether student or teacher perspectives were more accurate, both groups reported using the metacognitive strategies at least some of the time as instructed.

\section{Ruling out practice time as a confound with condition}

Self-reports of practice amounts were examined to see whether condition was confounded with amount of practice. Between subject $t$-tests showed no differences in reported practice amount at recording Time 1 [number of practice session: $t(33)<1$; length of practice sessions: $t(33)=-1.15, p=n s]$ nor Time 2 [number of practice sessions: $t(33)<1$; length of practice sessions: $t(33)<1]$. Table 1 presents means and standard deviations.

Furthermore, within subject $t$-tests showed students in Order did not change the number of practice sessions per week between conditions [Order 1: $t(12)=1.7, p=n s$; Order 2: $t(22)=-1.95, p=n s]$ nor length of practice session between conditions [Order 1: $t(12)=.547, p=n s ;$ Order 2: $t(22)=-1.18, p=n s]$ (see Table 1). Thus, performance differences by condition could not be attributed to differences in amount of practice. Examination of the raw data (see Table 2) reveals that very few students are practicing more than an hour a week.

\section{Ratings of performance recordings}

Between-subject $t$-tests at recording Time 1 showed that students first receiving metacognitive teaching (Order 1) significantly outperformed students who received control teaching first (Order 2) in rhythm $[t(33)=2.08, p=.05, d=.75]$ and marginally in musicality $[t(33)=1.9, p=.06, d=.65]$, but not in errors $[t(33)<1]$; see Table 3 for means and standard

Table 1. Average practice sessions and lengths per week in metacognitive and control conditions

\begin{tabular}{|c|c|c|c|c|}
\hline & \multicolumn{2}{|c|}{$\begin{array}{c}\text { Order } 1 \\
\text { (metacognitive-control) }\end{array}$} & \multicolumn{2}{|c|}{$\begin{array}{c}\text { Order } 2 \\
\text { (control-metacognitive) }\end{array}$} \\
\hline & Meta & Control & Meta & Control \\
\hline \multicolumn{5}{|c|}{ Number of practice sessions } \\
\hline$M$ & 3.3 & 3.0 & 3.0 & 3.2 \\
\hline$S D$ & 0.8 & 0.9 & 0.8 & 0.8 \\
\hline \multicolumn{5}{|c|}{ Length of practice session } \\
\hline$M$ & 2.6 & 2.5 & 2.6 & 2.7 \\
\hline$S D$ & 0.6 & 0.8 & 0.6 & 0.6 \\
\hline
\end{tabular}

Note: Number of session coding: $1=$ no practice, $2=1-2$ sessions, $3=3-4$ sessions, $4=5-6$ sessions, $5=7+$ sessions. Length of session coding: $1=0$ minute, $2=1-20$ minutes, $3=21-40$ minutes, $4=51-60$ minutes, $5=61+$ minutes. 
Table 2. Practice information from teaching conditions

\begin{tabular}{lccrr}
\hline & \multicolumn{2}{c}{ Metacognitive } & & \multicolumn{2}{c}{ Control } \\
\cline { 2 - 3 } & $N$ & $\%$ & & $N$ \\
\hline Ave. number of practice sessions per week & & \\
0 & 3 & 3 & 4 & 4 \\
$1-2$ & 22 & 20 & 15 & 14 \\
$3-4$ & 51 & 46 & 52 & 49 \\
$5-6$ & 25 & 22 & 29 & 27 \\
$7+$ & 11 & 10 & 7 & 7 \\
Total & 112 & 100 & 107 & 100 \\
Ave. length of practice session & $($ minutes) & & \\
0 & 3 & 3 & 4 & 4 \\
$1-20$ & 47 & 42 & 39 & 36 \\
$21-40$ & 56 & 50 & 59 & 55 \\
$41-60$ & 6 & 5 & 4 & 4 \\
$60+$ & 0 & 0 & 1 & 1 \\
Total & 112 & 100 & 107 & 100 \\
\hline
\end{tabular}

Note: Based on students of five teachers, resulting in 112/140 returned sheets for Metacognitive and 107/140 for Control.

deviations and Figure 3. However, at recording Time 2, after all students received metacognitive teaching, these differences were no longer found, as the groups performed equally well \{rhythm: $[t(33)<1]$; error: $[t(33)<1]$; musicality: $[t(33)<1]$; see Table 3 \}. Although there may be some variation in ratings across instruments that could be part of between condition performance differences, the small sample size per condition per instrument does not allow for analyses of condition effects at the instrument level.

To better understand these between condition differences and address potential baseline group differences or instrument effects, within sample $t$-tests showed that students in Order 2 (control-metacognitive) improved significantly following the metacognitive teaching in all rating categories \{rhythm: $[t(22)=4.53, p=.001, d=.76]$; error: $[t(22)=3.87, p=.001$, $d=.77]$; and musicality: $[t(22)=4.40, p=.001, d=.65]$; see Figure 3 and Table 3 for means and standard deviations . However, Order 1 (metacognitive-control) performed equally in all category ratings through both conditions \{rhythm: $[t(12)<1]$; error: $[t(22)<1]$; and musicality: $[t(22)<1]$; see Table 3 for means and standard deviations $\}$. Overall, the data are consistent with a general performance benefit of being exposed to metacognitive instruction whether it occurs early or late and that is maintained later during traditional instruction.

\section{Instructor post-lesson comments}

Overall, comments from instructors noted the positive impact of metacognitive teaching on their students. Comments shown
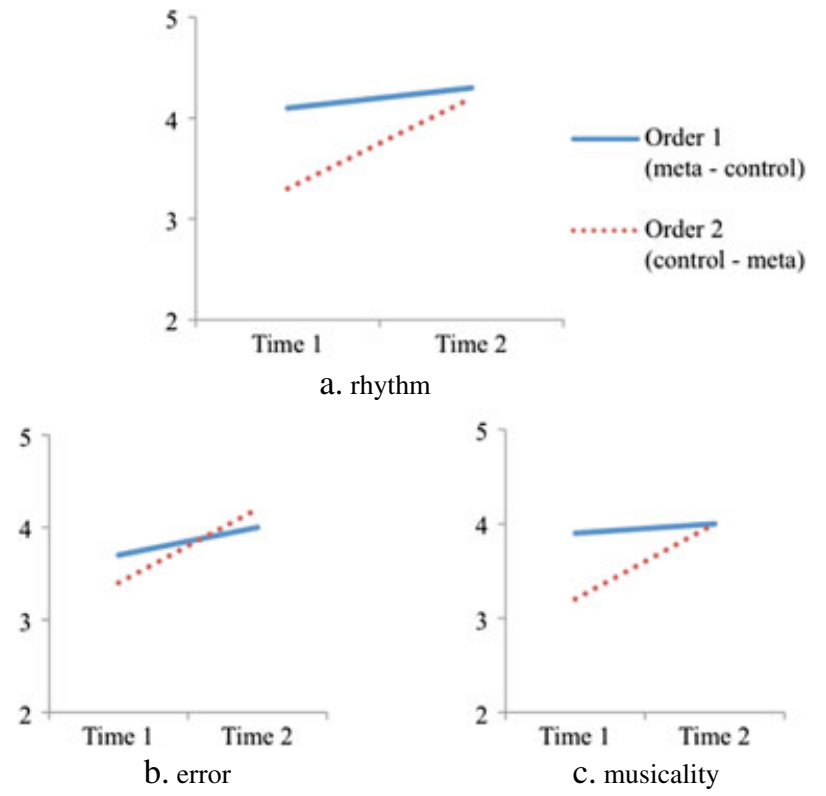

Figure 3. Mean performance ratings on rhythm, error, and musicality across Time 1 and Time 2 recordings

in Table 4 are most representative of descriptions provided by teachers regarding the implementation of metacognitive teaching: many but not all students were reported to benefit from the metacognitive teaching.

\section{Self-efficacy}

A portion of the students did not return all three self-efficacy measures (baseline, post-metacognitive teaching, post-control teaching) and had to be excluded from this analysis, resulting in 26 full sets of data. Contrary to predictions, self-efficacy did not change specifically following metacognitive teaching, nor did it change in general with instruction. Although the groups were significantly different at baseline measurements with those in the metacognitive-control order having higher baseline self-efficacy $(M=92, S D=26)$ than the control-metacognitive students $(M=71, \quad S D=36)$ $[t(43)=-2.31, p=.03]$, an ANCOVA yielded no significant change in self-efficacy across conditions for either Order, $F$ 's $<1$; see Table 5 for means and standard deviations.

\section{DISCUSSION}

Relatively few intervention studies have been conducted in real learning environments. Much of what is known about practical applications of the cognitive psychology of expertise

Table 3. Means and standard deviations of performance ratings

\begin{tabular}{|c|c|c|c|c|c|}
\hline & & \multicolumn{2}{|c|}{$\begin{array}{c}\text { Order } 1 \\
\text { (metacognitive-control) }\end{array}$} & \multicolumn{2}{|c|}{$\begin{array}{c}\text { Order } 2 \\
\text { (control-metacognitive) }\end{array}$} \\
\hline & & $M$ & $S D$ & $M$ & $S D$ \\
\hline \multirow[t]{2}{*}{ Rhythm } & Metacognitive & 4.1 & 1.1 & 4.2 & 1.3 \\
\hline & Control & 4.3 & 0.8 & 3.3 & 1.1 \\
\hline \multirow[t]{2}{*}{ Error } & Metacognitive & 3.7 & 0.8 & 4.2 & 1.2 \\
\hline & Control & 4.0 & 0.7 & 3.4 & .9 \\
\hline \multirow[t]{2}{*}{ Musicality } & Metacognitive & 3.9 & 0.9 & 4.0 & 1.3 \\
\hline & Control & 4.0 & 0.8 & 3.2 & 1.2 \\
\hline
\end{tabular}


Table 4. Instructor comments from post-lesson forms

Comment from post-lesson form

'[This student] never practiced before until we began the metacognitive lessons.'

'She was very receptive to the metacognitive study and was thrilled to find a new way to 'see' music'

'Metacognitive skills helped him to see the patterns and he was able to play the first piece.'

'This student plays various instruments and excels in each one. Metacognitive ideas and strategies were not very well received.'

'... she has been in performances and employs metacognitive skills often to memorize and perform music.'

'...she loved the metacognitive challenge, as she performed in this study.'

'I'm finding with the metacognitive technique, students are most resistant to practicing the different part [breaking the song into pieces].'

Table 5. Self-efficacy means and standard deviations for baseline and post-conditions

\begin{tabular}{lccccccc}
\hline & \multicolumn{3}{c}{$\begin{array}{c}\text { Order } 1 \\
\text { (metacognitive-control) }\end{array}$} & & \multicolumn{3}{c}{$\begin{array}{c}\text { Order 2 } \\
\text { (control-metacognitive) }\end{array}$} \\
\cline { 2 - 3 } & Baseline & Meta & Control & & Baseline & Meta & Control \\
\hline$M$ & 5.7 & 5.4 & 5.5 & & 4.9 & 4.7 & 4.6 \\
$S D$ & 0.8 & 0.9 & 0.9 & & 0.7 & 0.8 & 0.9 \\
\hline
\end{tabular}

Note: Order 1 based on 16 full sets; Order 2 based on 10 full sets.

development comes from intervention studies in the lab and correlational studies in the field. This study has bridged those divides to find actual learning benefits of a cognitive-based intervention in the field with traditional instructors and traditional learners. The effect of metacognitive teaching presented here produced several key results. First, metacognitive teaching had a positive effect on student performance. Students significantly improved their scores following metacognitive teaching, outperforming control (business as usual) teaching, and maintained their performance gains even when external instruction returned to the control format. Second, although students at this level of musical development did not previously seem to employ reflective skills during practice, they benefited from explicit guidance towards the reflection and evaluation of their process and progress. That is, developing a focus on the 'process-level' of playing (Berardi-Coletta et al., 1995) is attainable in novices rather than being only possible with experts who have richer domain representations.

Metacognitive monitoring seems pivotal because the majority of student practice occurs outside of the lesson. As many novices are often found to be unaware of errors in their learning and practice (Hallam, 2001a, 2001b; Kruger \& Dunning, 1999; Tobias \& Everson, 2002), coming to actively monitor one's knowledge and progress can help learners more accurately evaluate the material and skills. Awareness of these factors allows novices to direct their practice towards developing new skills more efficiently in the time between their lesson instructions, moving them towards expertise (Tobias \& Everson, 2002).

Interestingly, during the training sessions, a few instructors mentioned feeling that they were already using some metacognitive teaching in their lessons. Such misalignments between teacher statements and student perceptions have previously been found in literature relating to practice and may also be occurring in metacognitive instruction. Jorgensen (2000) found that $40 \%$ of students entering a music academy reported their instrumental instructors placing 'very little' or 'no' emphasis on practice strategies. In contrast, instructors report 'always' or 'almost always' teaching specific techniques for practice (Barry \& McArthur, 1994). A shared perspective on the teaching process may be crucial for students to effectively integrate the techniques proposed by the instructors into student practice.

Although teachers were likely using some degree of metacognitive instruction, the results suggest that students were not adopting such strategies in either sufficient complexity or frequency. It was not until metacognitive processes and reflective practice were made regularly explicit to students that their performance improved. Perhaps although instructors are aware of each student's strengths and weaknesses and may adjust their teaching accordingly, the student does not necessarily perceive these considerations and then do not transfer these elements to their own practice. Having students become more active in guiding their own learning - verbalizing their progress and identifying strategies that work best for their musical development - appears to result in more successful achievement.

It is worth noting that the benefit in performance was achieved without a change in the reported quantity of practice, suggesting that metacognition leads to more efficient practice rather than simply more practice overall. We are not suggesting that metacognition is more important than practice amount nor that high levels of performance can be reached without additional practice. Rather, these data allow us to conclude that the use of metacognitive strategies produces efficiency gains in learning, whereas other forms of improved study methods might require significantly more total time to produce advantages.

Deepening the structure and thoughtfulness involved in student practice is likely especially useful in the population that was studied. Given the overall low practice time that results from the various challenges to practice typically faced by adolescents (e.g. increased peer relations, alternative activity choices, schoolwork), increasing the potency of their practice may greatly influence their musical achievement. Additionally, students involved in less formal music education than students in highly rigorous musical training often have less frequent contact with their instructors (e.g. once a week versus daily). Promoting reflection during practice processes can help students benefit more from their instructional experience both in and out of the lesson.

Contrary to our hypothesis, self-efficacy did not increase following metacognitive teaching. An increase in students' reflection and verbalization of the effective strategies was expected to cause a boost in self-efficacy once students were able to clearly understand how practice might be most effective for their needs. However, this self-efficacy gain was not found, possibly for a number of reasons. First, few students returned all self-efficacy forms, limiting our comparison power. Secondly, students in our current population may have poorly estimated their performance ability initially, some too high and some too low, with increases in reflection simply correcting these biases rather than shifting overall estimates in one direction. Indeed, the overall mean self-efficacy at baseline was relatively high ( $5 \mathrm{~s}$ and $6 \mathrm{~s}$ on a seven-point scale); the 
metacognitive literature in general notes that novices are often over-confident (Kruger \& Dunning, 1999). Through more careful metacognitive evaluations, students may have appropriately adjusted their self-efficacy ratings downward. Third, perhaps the duration of the study was too short to capture significant changes in self-efficacy that will result from improved practice strategies accumulating and performance growth becoming more noticeable. Additional measurements collected later as metacognitive practice continues may be necessary to demonstrate these potential differences.

\section{Future directions}

In this study conducted in real music practice contexts, we did not obtain direct measures of student practice strategies. A lab study would be required to more precisely document the learning strategies students used in their lessons and practice before and after metacognitive teaching. A related follow-up study goal involves examining the ways in which interaction between instructor and student change through encouraging metacognition in students.

Before suggesting broad implementation of metacognitive teaching on the basis of our results, replications are needed across various performance songs, student populations, and teacher populations to examine the robustness and reliability of our observed effect. Perhaps some kinds of performance pieces benefit more from metacognitive reflection than other pieces, and perhaps some student or teacher populations have trouble implementing metacognitive processes.

Importantly, although music students were selected as an instance of how metacognitive teaching may improve performance, our study design may be applicable to other domains, as well, such as mathematics learning or sports practice. Although metacognition is typically developed later in one's progression towards expertise, our results suggest that prompting novice students to be explicitly reflective earlier may produce deeper learning and better skill advancement. Additionally, through helping students practice and perform well, perhaps their overall enjoyment and persistence may increase and affect future practice down the road (Costa-Giomi, Flowers, \& Sasaki, 2005). Further studies will help illuminate the potential impact metacognitive teaching may have on students' internal factors, practice time, and practice techniques.

\section{REFERENCES}

Barry, N. H., \& Hallam, S. (2002). Practice. In R. Parncutt, \& G. E. McPherson (Eds.), The science and psychology of music performance: Creative strategies for teaching and learning. (pp. 151-165). New York: Oxford University Press, Inc.

Barry, N. H., \& McArthur, V. (1994). Teaching practice strategies in the music studio: A survey of music teachers. Psychology of Music, 22, 44-55. DOI: 10.1177/0305735694221004.

Berardi-Coletta, B., Buyer, L. S., Dominowski, R. L., \& Rillinger, E. R. (1995). Metacognition and problem solving: A process-oriented approach. Journal of Experimental Psychology: Learning, Memory, and Cognition, 21(1), 205-223.

Cantwell, R. H., \& Millard, Y. (1994). The relationship between approach to learning and learning strategies in learning music. British Journal of Educational Psychology, 64, 45-63.

Chi, M. T., Feltovich, P. J., \& Glaser, R. (1998). Categorization and representation of physics problems by experts and novices. Cognitive Science, 5(2), $121-152$
Costa-Giomi, E., Flowers, P. J., \& Sasaki, W. (2005). Piano lessons of beginning students who persist or drop out: Teacher behavior, student behavior, and lesson progress. Journal of Research in Music Education, 53(3), 234-247.

Duke, R. A. (1999/2000). Measures of instructional effectiveness in music research. Bulletin of the Council for Research in Music Education, 143, 1-48.

Eccles, D. W., \& Feltovich, P. J. (2008). Implications of domain-general "psychological support skills" for transfer of skill acquisition of expertise. Performance Improvement Quarterly, 21(1), 43-60. DOI: 10.1002/piq.20014

Ericsson, K. A., Krampe, R., \& Tesch-Romer, C. (1993). The role of deliberate practice in the acquisition of expert performance. Psychological Review, 100(3), 363-406.

Flavell, J. H. (1979). Metacognition and cognitive monitoring: A new area of cognitive-development inquiry. The American Psychologist, 34(10), 906-911.

Grumko, J. E. (1993). Perceptual differences between expert and novice music listeners: A multidimensional scaling analysis. Psychology of Music, 21, 34-47.

Hallam, S. (2001a). The development of expertise in young musicians: Strategy use, knowledge acquisition and individual diversity. Music Education Research, 3(1), 7-23. DOI: 10.1080/14613800020029914

Hallam, S. (2001b). The development of metacognition in musicians: Implications for education. British Journal of Music Education, 18(1), 27-39.

Jorgensen, H. (2000). Student learning in higher instrumental education: Who is responsible? British Journal of Music Education, 17(1), 67-77.

Kruger, J., \& Dunning, D. (1999). Unskilled and unaware of it: How difficulties in recognizing one's own incompetence lead to inflated self-assessments. Journal of Personality and Social Psychology, 77(6), 1121-1134.

Lehmann, A. C., \& Ericsson, K. A. (1997). Research on expert performance and deliberate practice: Implications for the education of amateur musicians and music students. Psychomusicology, 16, 40-58.

Lesgold, A., Rubinson, H., Feltovish, P., Glaser, R., Klopfer, D., \& Yen, W. (1988). Expertise in a complex skill: Diagnosing x-ray pictures. In M. T. H. Chi, R. Glaser, \& M. J. Farr (Eds.), The Nature of Expertise (pp. 311-342). Hillsdale, NJ: Erlbaum.

McPherson, G. E. (2005). From child to musician: Skill development during the beginning stages of learning an instrument. Psychology of Music, 33 (5), 5-35. DOI: 10.1177/0305735605048012

McPherson, G. E., \& McCormick, J. (2006). Self-efficacy and music performance. Psychology of Music, 34(3), 322-336. DOI: 10.11770305735606064841.

McPherson, G. E., \& Renwick, J. M. (2001). A longitudinal study of self-regulation in children's musical practice. Music Education Research, 3(2), 169-186. DOI: 10.1080/1461380012008923 2

Palmer, C., \& Meyer, R. K. (2000). Conceptual and motor learning in music performance. Psychological Science, 11(1), 63-68.

Parncutt, R., \& McPherson, G. (Eds.), (2002). The science and psychology of music performance: Creative strategies for teaching and learning. Oxford: Oxford University Press.

Pintrich, P. R. (2002). The role of metacognitive knowledge in learning, teaching, and assessing. Theory Into Practice, 41(4), 219-225.

Ritchie, L., \& Williamon, A. (2007). Measuring self-efficacy in music. In A. Williamon, \& D. Coimbra (Eds.), Proceedings of the International Symposium on Performance Science 2007, European Association of Conservatoires (AEC).

Siegler, R. S. (1996). Emerging minds: The process of change in children's thinking. New York: Oxford University Press.

Sherer, M., Maddux, J. E., Mercandante, B, Prentice-Dunn, S., Jacobs, B., \& Rogers, R. W. (1982). Self-efficacy scale: Construction and validation. Psychological Reports, 51, 663-671.

Sloboda, J. A., Davidson, J. W., Howe, M. J. A., \& Moore, D. G. (1996). The role of practice in the development of performing musicians. British Journal of Psychology, 87(2), 287-309.

Sternberg, R. J. (1998). Metacognition, abilities, and developing expertise: What makes an expert student? Instructional Science, 26, 127-140.

Tobias, S., \& Everson, H. T. (2002). Knowing what you know and what you don't: Further research on metacognitive knowledge monitoring. College Board Research Report No. 2002-3. College Entrance Examination Board, New York.

Zimmerman, B. J. (1998). Academic studying and the development of personal skill: A self-regulatory perspective. Educational Psychologist, $33(2 / 3), 73-86$.

Zimmerman, B. J. (1988). Self-regulated learning and academic achievement An overview. Eduational Psycholigist, 251, 3-17. 